\title{
What's so social about Social Return on Investment? A critique of quantitative social accounting approaches drawing on experiences of international microfinance
}

\begin{abstract}
Quantitative approaches figure prominently in social accounting and auditing. This is because of the preference among many investors for simple and ostensibly robust and comparative metrics. Social Return on Investment (SROI), which produces a monetised value for social impact generated per unit of currency invested, has emerged as one of the dominant tools to generate such metrics. This article discusses the merits of this increasing orientation towards quantitative metrics in social accounting using SROI as an exemplar and drawing on an extensive review of social impact evaluations in microfinance. The microfinance sector represents an interesting and relevant case for social accounting because it has been strongly orientated towards quantitative and experimental methods to evaluate its non-financial performance. The article concludes that, despite using sophisticated methods, the microfinance sector struggles to credibly determine its impact on customers. Self- and MFI selection biases cast doubts on the merits of using national benchmark indicators or control groups. Consequently, it is argued that SROI is better viewed as a means of claiming symbolic legitimacy (as per Luke, Barraket, and Eversole 2013) than as a robust method for evidencing social impact or a tool for managers and investors.
\end{abstract}

Key words: Social accounting and auditing; Social impact reporting; Social Return on Investment; Microfinance

\section{Introduction}

Social accounting and auditing (SAA) constitute an important framework for demonstrating social and non-financial performance, contribution and impact of mission-driven organisations for investors and stakeholders. This is because conventional financial accounting undervalues or fails to capture the contribution made by these organisations. Social auditing can be defined as:

... a voluntary, ongoing, embedded organizational process, internally controlled but externally verified, that involves stakeholders in the measurement and reporting of their perceptions of the organization's social performance to internal and external stakeholders (Greenwood and Kamoche 2013,725 , emphasis in original)

One of the most influential methods within SAA is Social Return on Investment (SROI), which monetises social outcomes and expresses them as a ratio related to the investment made (i.e. value generated per unit invested). The ascension of SROI is an outcome and manifestation of the wider appeal of quantitative methods and metrics. Quantitative approaches are believed to produce simple and ostensibly comparative and robust metrics that enables benchmarking and a seemingly objective basis for performance management. For these reasons, SROI is 'popular in the impact investment community' (Ebrahim and Rangan 2014, 134). Yet quantitative metrics do not necessarily fit easily with the complexity of social outcomes. It is often difficult to find standardised and comparative data that meaningfully capture social outcomes 
(Frumkin 2003; Gibbon and Dey 2011).This article draws on a critical examination of the attempts to identify and quantify the impact of Microfinance Institutions (MFIs) to critique SROI. As such it aims to make a contribution to understanding the tensions in the increasing orientation towards quantitative approaches. The experience of the microfinance sector is relevant and fruitful because it represents a large missiondriven sector that has drawn extensively on quantitative approaches to demonstrate its social performance.

The remainder of this paper is organised into five sections. The second section outlines the background, assumptions, purpose and application of SROI. The third discusses impact assessments within microfinance, while the fourth sets out the main methodological lessons that can be drawn from these assessments. The final section concludes with a discussion of the role and potential applications of SROI in light of these methodological lessons.

\section{Social Return on Investment}

SROI was developed in the US in the late 1990s by the Roberts Enterprise Development Fund (REDF) to capture and monetise the full value creation of its employment programme and has since become one of the dominant social performance frameworks in the social enterprise sector (Gibbon and Dey 2011). The SROI methodology developed REDF was based on a blended value model, which stated that an organisation could achieve both economic success and social benefits (Gair 2002). The SROI was subsequently adapted for the UK by the New Economics Foundation (NEF) which devised a 10-stage approach (Somers et al. 2005). The model was adapted to a six-stage methodology by the Cabinet Office (Nicholls et al. 2009).

The SROI methodology is claimed to fulfil a number of purposes. First, SROI is claimed to be a management tool that can be used to enhance the impact of the organisation by channelling organisational efforts and resources into high-impact activities (Nicholls et al. 2009). In fact, one of the ways in which SROI is believed to differ from cost-benefit analysis is that it is designed 'as a practical management tool' (Gibbon and Dey 2011, 2). According to the guidance issued by the Cabinet Office, SROI 'can help guide choices that managers face when deciding where they should spend time and money' (Nicholls et al. 2009, 10).

Second, SROI is believed to constitute empirical evidence of the effectiveness and impact of social enterprises and their activities (Nicholls et al. 2009; Somers et al. 2005). Arvidson et al $(2010,10)$ argue that 'SROI contributes to how we can appreciate impact (prove).' If a SROI analysis proves the impact of one organisation and its activities, then presumably a collection of SROI studies within one sector will inform our understanding of the extent and nature of impact of the sector as a whole.

Third, SROI is claimed to be a tool for investors on which they can rely to channel investments into organisations and sectors that produce greater impacts in desired areas (Somers et al. 2005). It can also 'help show how investment can maximise impact' (Nicholls et al. 2009, 11). According to the guide on SROI by the Cabinet Office (Nicholls et al. 2009, 11): 'Bodies that commission social value or invest in the creation of social value can use SROI initially as a way to help them decide where to 
invest, and later to assess performance and measure progress over time.' The SROI analysis can be evaluative, assessing the impact and effectiveness of an intervention, or a forecast to determine where to invest (Nicholls et al. 2009).

SROI is in many respects similar to the classical cost-benefit (Arvidson et al. 2010; Gibbon and Dey 2011). In an SROI analysis the emphasis is on identifying outcomes related to the investment made, which is then expressed as a ratio in the form of the value generated per unit of currency invested, net of cost. SROI involves the quantification and comparison of costs and benefits, and the benefits must outweigh the costs to warrant investment in the activity in question. Similar to the cost-benefit analysis, SROI involves estimating future benefits and costs, and arriving at a figure expressed in current terms by using discounting. In both methods, the costs and benefits are expressed as monetary units, and they can be tangible (e.g. price of asset, income from service) or intangible (e.g. increased well-being) (Gair 2002). However, SROI differs from the cost-benefit analysis in some important respects, such as greater emphasis on stakeholder involvement (Arvidson et al. 2010) and greater use as a management tool (Gibbon and Dey 2011).

One of the most important aspects of SROI is that it links the services and products of an organisation with outcomes for individuals and groups that are not part of the organisation. On the one hand, there are the financial inputs (i.e. investment, costs) that relate to the organisation. On the other, there are the monetised social outputs that relate to individuals and groups that benefit from service. This differentiates it from financial returns, such as return on equity and return on assets, which are calculated from components internal to the organisation, though they will be affected by external factors.

This link makes isolating the impact of the intervention or services in question - by linking the services provided the organisation to the outcomes of the recipients - of great importance. As a method, SROI relies on a non-experimental approach using control groups or a benchmark to determine what would have happened in the absence of the intervention (i.e. deadweight) (Nicholls et al. 2009; Somers et al. 2005). According to the SROI guide by the Office of the Third Sector: 'To calculate deadweight, reference is made to comparison groups or benchmarks...you need to seek out information that is as close to your population as possible. The more similar the comparison group, the better the estimate will be' (Nicholls et al. 2009, 56).

In addition, a SROI analysis should consider displacement and the duration of the impact (i.e. drop-off and discounting). Finally, the analyst must consider what proportion of the change is attributable to the organisation. These are used to convert the outcomes identified, described, quantified and collected in the first steps of the process into actual impacts. There is also a general emphasis on basing all assumptions, as far as possible, on empirical evidence (Nicholls et al. 2009).

Although SROI takes into account some negative externalities, discounting and displacement, which may, in theory, lead to a negative impact, the underlying assumption is that, at the core, there is a positive impact and that the organisation is, in part, responsible for that impact (Arvidson et al. 2010; Nicholls et al. 2009; Ryan and Lyne 2008). If a particular outcome is identified as a likely or intended impact at the start of the process then it is given a positive value which is then reduced through 
discounting, displacement and assignment of attribution. Ryan and Lyne (2008, 223) argue that the failure of applying SROI-type analysis leads to a disregard for the benefits produced by the social enterprise sector:

The partial application of these techniques [classical cost-benefit analysis] to social enterprise is possible, because they often sell a product or a service, but they fail to capture adequately the additional social value added by the activities of social enterprises. This is important because the true value of investment in social enterprise is often understated or even unrecognised

A major issue with the SROI methodology is that it does not allow for comparisons between different studies and interventions (Emerson and Cabaj 2000; Gibbon and Dey 2011). This is because studies apply different ratios and techniques for estimating deadweight and attribution, and apply different time periods and discounting rates (Banke-Thomas et al. 2015; Luke, Barraket, and Eversole 2013). This problem is compounded by the emphasis on monetising social outcomes that cannot be easily monetised (Frumkin 2003). Gibbon and Dey $(2011,63)$ note that the 'use of such proxies is highly subjective, especially when dealing with 'softer" outcomes.'

Luke, Barraket, and Eversole (2013) argue that SROI is used to quantify measures in order to claim symbolic legitimacy rather than to generate substantive information on actual performance. They argue that the value of SROI performance calculations and measures can be improved by restricting the analysis to 'clearly identifiable and reliable measurable costs and benefits' (Luke, Barraket, and Eversole 2013, 242). Furthermore, they recommend using measures drawing on internationally recognised accounting principles comparable across time and organisations as well as including opportunity costs. Banke-Thomas et al (2015) add that SROI studies should provide justification for discount rates used in models, rely on PPP equivalent and incorporate case-control or before and after designs to account for outcomes.

\section{Microfinance Impact Assessments}

Driven largely by investors and funders, quantitative approaches have dominated the evaluation of social performance of the international microfinance sector.

Consequently, studies of the impact of MFIs and the methodological considerations of such studies probably constitute the largest body of peer-reviewed research outputs in the field of microfinance. As with SROI, these evaluations attempt to link the services provided by an organisation to the outcomes for the recipients.

The most widely used method of isolating the impact of microcredits from other potential sources of change has been to use a control group. Among the most common approaches of selecting a control group has been to select non-client households with similar observable socioeconomic characteristics (e.g. quality of housing, ownership and size arable land) (Meyer 2008). Often these non-client households are from an area without an MFI branch as MFIs may have spillover effects beyond the client households (employment opportunities created by client businesses). Another method to isolate the impact of microcredits has been to compare clients with incipient or pipeline clients (i.e. households whose applications have been approved but have yet to receive a loan). The perceived advantage of this approach is that incipient and pipeline clients may be expected to be more similar to existing clients than non-clients 
as they have actively sought credit and have been approved unlike non-clients (Mosley and Rock 2004). Numerous studies show that clients tend to be wealthier than non-clients (e.g. McKernan 2002; Pitt et al. 1999).

Over the past few years, these two approaches have been heavily criticised for not controlling for two important selection biases (Meyer 2008). First, there is the socalled self-selection bias, which implies that the households that resort to microfinance may be inherently different from households that do not make use of microfinance. Many of these differences may be unobservable, such as risk aversion and entrepreneurial acumen. This also applies to pipeline or incipient clients, as the fact that they have sought finance later than the established clients may indicate differences in risk aversion level and entrepreneurial acumen. This problem may be circumvented by using a control location, though this does not control for the MFIselection bias discussed below.

Second, there is the MFI - or programme-selection bias. The selection of areas to operate in and clients by MFIs is not a random process. Clients are selected through a careful screening process to establish creditworthiness, so the likelihood of success may be a pre-condition rather than an outcome of access to credit (Gaile and Foster 1996). Comparing non-clients and clients may thus produce a biased result. Similarly, the selection of an area to set up an MFI office or branch is also likely to be based on an assessment of need and feasibility and therefore not random. Thus even where the researcher operates with a control location there is a risk of bias because there may be inherent differences between an MFI-location and a control location.

The best way to circumvent these biases, according to these critics, is to move towards an experimental research design where the access to credit or location of MFI is random (Meyer 2008). These studies are called randomised or experimental impact assessments. In theory, by randomising access to MFI services, a comparison of recipients and non-recipients will yield a more accurate estimate of impact. In practice such experimental studies are often difficult to conduct. Few studies are truly randomised and most use so-called near-creditworthy MFI applicants (Fernald et al. 2008; Augsburg et al. 2015) or residents in areas randomly given an MFI branch (Coleman 1999; Angelucci, Karlan, and Zinman 2015) in their experiments.

Table 1 provides an overview of microfinance impact assessments by impact area, geographical area and whether study is experimental or not.

\section{[TABLE 1 HERE]}

In most cases, non-randomised studies find an impact in the intended direction. In particular, microfinance has been found to have an impact on female empowerment, poverty, income, and household consumption and expenditure. Some of these studies have also found remarkably large impact of microcredit. In one of the most extensive impact assessments in Bangladesh, Khandker et al (1998) find that 5\% of client households rose above the poverty line, which is an astonishing result especially given that the MFIs in question are largely self-sustaining. Amin et al (1994) find greater use and knowledge of contraceptives among microfinance clients in Bangladesh because of greater involvement of women in income generating activity. This finding seems echoed by Hashemi et al (1996), who detect significant impact of 
MFI membership on female empowerment in part through creating opportunities for women to earn independent incomes.

However, subsequent studies start recognising the potential shortcomings of simple comparisons between clients and non-clients. McKernan (2002), for example, argues that researchers may be introducing a considerable bias and overestimating effects of participation on profits because more profitable households are more likely to participate in the first place. Controlling for such bias, McKernan nevertheless finds positive and significant effects of participation on business profits. Similarly, Pitt et al (1999) analyse the dataset of Khandker et al applying a set of controls for choicebased sampling, self-selection and non-random programme placement, and find no impact of microcredit on female fertility and some impact on male fertility. They show that statistical analyses not controlling for these biases produce biased results.

Because of the potential biases in impact assessments drawing on comparisons between clients and non-clients, there has generally been a move towards so-called randomised or experimental studies. There have been two types of such studies. First, there have been studies based on comparing households in areas randomly allocated an MFI branch. This was first done by Coleman (1999) in Thailand who found no significant impacts of microfinance on the households or businesses. This has since been replicated in a number of studies (e.g. Tarozzi, Desai, and Johnson 2015; Attanasio et al. 2015; Crépon et al. 2015; Banerjee et al. 2015). The second type of randomised studies randomly allocates credit or a review of the application to applicants marginally not meeting the lending criteria (Fernald et al. 2008; Augsburg et al. 2015; Karlan and Zinman 2010). These randomised studies suggest that there is an over-estimation of impact in simple comparisons with control group or benchmarks. Especially, these studies cannot find any evidence for transformational impacts on poverty shown in early, non-randomised studies. Randomised studies do show some positive impacts on business profits, income and investment. However, they also uncover important negative impacts on health, asset endowment and indebtedness.

\section{Implications and lessons for SROI}

The most salient observation from the review of the microfinance literature is that straightforward comparisons of clients and non-clients do not necessarily reflect true impact. The difficulty is selecting a control group similar to the treatment group (i.e. microfinance clients) in all aspects save the use of microfinance to isolate the impact of microcredits. After all, the access to microcredits is the outcome of a screening process by an institution that may have carefully selected a location to operate. Moreover the borrowing household has itself decided to take out the loan and may differ from the control group household on a number of unobservable traits such as risk aversion, entrepreneurial acumen and initiative.

However, the extent to which this observation applies to other sectors is likely to depend on the level of user initiative required to access the service and the level of screening required to grant access. It is argued that the experience and evidence from the microfinance impact evaluations may apply in circumstances in which the access to services requires high levels of user initiative and is subject to high levels of screening (Figure 1). 


\section{FIGURE 1 HERE}

This is because these two characteristics are likely to increase self-selection and programme-selection biases. First, where the access to services is rationed and subject to screening of potential clients or targeting of a particular set of clients, there is a risk of programme-selection bias distorting simple comparisons with benchmarks or nonrandom control groups. In other words, the granting of access to a service is not random but the outcome of a purposive selection process. In some cases, services may be reserved for clients within the target group that will be able to make the most of the service in question. This may, for example, often be the case for enterprise support where services may be offered to people with viable business propositions or with entrepreneurial potential. In these cases, the likelihood of success may be a precondition for access rather than an outcome of the service. This may distort any SROI analysis because the treatment group will be more likely to succeed than the control group or benchmark.

Second, the level of initiative and interest required on part of the user or his or her network may determine the extent to which a non-randomised research design biases results. Users of some services will actively have to seek out the service provided by the organisation or the inclusion of someone in a particular programme or intervention may be the result of resourceful relatives and networks. These people may well be inherently different from those that chose not to access these services. For example, the people attending pension club lunches aimed at reducing isolation, may, based on the fact that they have actively sought to participate in such events, be more inclined to socialise than those that chose not to participate. Comparing the attendees of these lunches with non-participants is likely to inflate the impact of the intervention on the users. This may make any comparison with a non-randomised control group biased.

\section{Conclusions and recommendations}

The popularity of SROI, compared with many other social accounting tools, in measuring and reporting social impact of mission-driven organisations is linked to the enduring appeal of quantitative methods and metrics. Statistical data appear more robust and scientific compared with 'softer', qualitative measures, and lend themselves to standardisation and, hence, benchmarking of performance. Yet it is often difficult to find standardised and comparative data that meaningfully capture social outcomes (Frumkin 2003; Gibbon and Dey 2011). This article delves into these arguments through critiquing SROI based on an extensive review of impact evaluations in the microfinance sector, which has used quantitative methods to assess it social performance to a greater degree than perhaps any other sector.

It concludes that, for all the methodological sophistication of these impact evaluations, the link between the services provided by MFIs and outcomes for customers remains elusive. This is because of the difficulty in distinguishing between inherent characteristics of users and outcomes generated by the access to microfinance. This, it is argued, casts doubts on the robustness of SROI as methodology to assess social impact. SROI relies on comparisons between beneficiaries and benchmark rates or control groups and then subtracting deadweight (what would have happened in the absence of the intervention) and displacement 
(crowding out effects). Yet, experimental studies in microfinance suggest that simple comparisons with non-users and benchmarks lead to overestimates of impact, and disregard the possibility that a service may have a negative impact. This is especially likely to be the case where access to services is subject to screening and where the user has to exercise considerable initiative in accessing services. In these cases, the starting point (i.e. the difference between users and the benchmark) may be biased and applying deadweight and displacement will not necessarily address this.

Consequently, investors should exercise caution in using SROI to determine the activities in which they invest, as a higher or lower SROI does not necessarily reflect greater or lesser social impact. As argued by Gibbon and Dey $(2011,64)$, singularly focusing on SROI 'may lead to a one-dimensional and arguably "dumbed-down" portrayal of the organisation's activities.' This also questions the usefulness of SROI as a management tool to guide the activities into which an organisation puts its efforts. In light of the problems of selecting a control group in non-experimental research, a higher SROI may reflect targeting and client selection rather than impact. Thus, an organisation wanting to boost investment and its SROI score may boost its score by targeting clients more likely to succeed.

Instead, practitioners may want to focus on enhancing their understanding of the trajectories and typologies of users. For example, in terms of microfinance, business support or employment schemes, case studies of users who stay unemployed or whose business fails combined with quantitative data on clients, may enable them to target post-service support at groups more likely to fail (timing, design of services). Where possible, investors should draw on the findings of randomised studies on the impact of the sector or activity to inform realistic expectations of the potential impact, including potential pitfalls, limitations and negative effects, of the activities of an organisation in which the investor is considering to invest. In addition, investors may find metrics on the beneficiaries (e.g. how well institution reaches target group, how well meets needs of most vulnerable groups) and on the institution itself (e.g. effective governance to prevent mission drift, efficiency of organisation) more reliable proxies social performance than SROI.

Where then does that leave SROI? Rather than attempting to make SROI more robust by incorporating case-control and justification for discount rates as suggested by Banke-Thomas et al (2015) or by relying on international accounting standards for measures as recommended by Luke et al (2013), there should be greater recognition of its limitations. It is argued that the role of SROI in context of social accounting is in claiming symbolic legitimacy, as per Luke et al (2013), for activities with no obvious or immediate pecuniary value. As such, it can help fulfil the role of social accounting 'as a "societal" accountability mechanism' (David et al. 2010, 956) by highlighting the potential monetary value of social outcomes.

\section{Bibliography}

Amin, Ruhul, A. U. Ahmed, J. Chowdhury, and M. Ahmed. 1994. "Poor women's participation in income-generating projects and their fertility regulation in rural Bangladesh: Evidence from a recent survey." World Development 22 (4):555-565. doi: http://dx.doi.org/10.1016/0305-750X(94)90111-2. 
Angelucci, Manuella, Dean Karlan, and Jonathan Zinman. 2015. "Microcredit Impacts: Evidence from a Randomized Microcredit Program Placement Experiment by Compartamos Banco." American Economic Journal: Applied Economics 7 (1):151-182.

Arvidson, Malin., Fergus. Lyon, Stephen. McKay, and Domenico. Moro. 2010. "The ambitions and challenges of SROI." Third Sector Research Centre Working Paper (49).

Attanasio, Orazio, Britta Augsburg, Ralph De Haas, Emla Fitzsimons, and Heike Harmgart. 2015. "The Impacts of Microfinance: Evidence from Joint-Liability Lending in Mongolia." American Economic Journal: Applied Economics 7 (1):90122.

Augsburg, Britta, Ralph De Haas, Heike Harmgart, and Costas Meghir. 2015. "The Impacts of Microcredit: Evidence from Bosnia and Herzegovina." American Economic Journal: Applied Economics 7 (1):183-203.

Banerjee, Abhijit, Esther Duflo, Rachel Glennerster, and Cynthia Kinnan. 2015. "The Miracle of Microfinance? Evidence from a Randomized Evaluation." American Economic Journal: Applied Economics 7 (1):22-53. doi: http://www.aeaweb.org/aejapplied/.

Banke-Thomas, Aduragbemi Oluwabusayo, Barbara Madaj, Ameh Charles, and Nynke van den Broek. 2015. "Social Return on Investment (SROI) methodology to account for value for money of public health interventions: a systematic review." BMC Public Health 15 (1):1-14. doi: 10.1186/s12889-015-1935-7.

Coleman, Brett E. 1999. "The impact of group lending in Northeast Thailand." Journal of Development Economics 60 (1):105-141. doi: http://dx.doi.org/10.1016/S0304-3878(99)00038-3.

Crépon, Bruno, Florencia Devoto, Esther Duflo, and William Parienté. 2015. "Estimating the Impact of Microcredit on Those Who Take It Up: Evidence from a Randomized Experiment in Morocco." American Economic Journal: Applied Economics 7 (1):123-150.

David, Collison, Dey Colin, Hannah Gwen, and Stevenson Lorna. 2010. "AngloAmerican capitalism: the role and potential role of social accounting." Accounting, Auditing \& Accountability Journal 23 (8):956-981. doi: 10.1108/09513571011092510.

Ebrahim, Alnoor, and V. Kasturi Rangan. 2014. "What impact? Aframework for measuring the scale and scope of social performance." California Management Review 56 (3):118-141. doi: 10.1525/cmr.2014.56.3.118.

Emerson, J., and M. Cabaj. 2000. "Social Return on Investment." Making Waves 11 (2):10-14.

Fernald, Lia C. H., Rita Hamad, Dean Karlan, Emily J. Ozer, and Jonathan Zinman. 2008. "Small individual loans and mental health: a randomized controlled trial among 
South African adults." BMC Public Health 8:409-409. doi: 10.1186/1471-2458-8409.

Frumkin, Peter. 2003. "Inside Venture Philanthropy." Society 40 (4):7-15.

Gaile, G. L., and J. Foster. 1996. Review of Methodological Approaches to the Study of the Impact of Microenterprise Credit Programs. AIMS.

Gair, C. 2002. A Report From the Good Ship SROI. The Roberts Foundation.

Gibbon, Jane, and Colin Dey. 2011. "Developments in Social Impact Measurement in the Third Sector: Scaling Up or Dumbing Down?" Social and Environmental Accountability Journal 31 (1):63-72. doi: 10.1080/0969160X.2011.556399.

Greenwood, Michelle, and Ken Kamoche. 2013. "Social accounting as stakeholder knowledge appropriation." J Manag Gov 17 (3):723-743. doi: 10.1007/s10997-0119208-z.

Hashemi, Syed M., Sidney Ruth Schuler, and Ann P. Riley. 1996. "Rural credit programs and women's empowerment in Bangladesh." World Development 24 (4):635-653. doi: 10.1016/0305-750X(95)00159-A.

Hossain, Mahabub. 1990. "Credit for alleviation of rural poverty: the Grameen bank in Bangladesh." Community development journal 25 (2):89.

Kaboski, Joseph P., and Robert M. Townsend. 2005. "POLICIES AND IMPACT: AN ANALYSIS OF VILLAGE- LEVEL MICROFINANCE INSTITUTIONS." Journal of the European Economic Association 3 (1):1-50. doi: 10.1162/1542476053295331.

Karlan, Dean, and Jonathan Zinman. 2010. "Expanding Credit Access: Using Randomized Supply Decisions to Estimate the Impacts." Review of Financial Studies 23 (1):433-464. doi: http://rfs.oxfordjournals.org/content/by/year.

Khandker, Shahidur R., Hussain A. Samad, and Zahed H. Khan. 1998. "Income and employment effects of micro-credit programmes: Village-level evidence from Bangladesh." The Journal of Development Studies 35 (2):96-124. doi: 10.1080/00220389808422566.

Luke, Belinda, Jo Barraket, and Robyn Eversole. 2013. "Measurement as legitimacy versus legitimacy of measures: Performance evaluation of social enterprise." Qualitative Research in Accounting \& Management 10 (3/4):234-258. doi: 10.1108/QRAM-08-2012-0034.

Masud Ahmed, Syed, Mushtaque Chowdhury, and Abbas Bhuiya. 2001. "MicroCredit and Emotional Well- Being: Experience of Poor Rural Women from Matlab, Bangladesh." World Development 29 (11):1957-1966. doi: 10.1016/S0305750X(01)00069-9.

McKernan, Signe-Mary. 2002. "The Impact of Microcredit Programs on SelfEmployment Profits: Do Noncredit Program Aspects Matter?" The Review of Economics and Statistics 84 (1):93-115. 
Meyer, R. L. 2008. "Measuring the impact of microfinance." In What's wrong with microfinance, edited by T. Dichter and M. Harper, 208-225. Rugby: Intermediate Technology Publications Ltd.

Mohindra, K., S. Haddad, and D. Narayana. 2008. "Can microcredit help improve the health of poor women? Some findings from a cross-sectional study in Kerala, India." International Journal for Equity in Health 7 (2).

Mosley, Paul, and June Rock. 2004. "Microfinance, labour markets and poverty in Africa: a study of six institutions." Journal of International Development 16 (3):467500. doi: 10.1002/jid.1090.

Nicholls, J., E. Lawlor, E. Neitzert, and T. Goodspeed. 2009. A guide to social return on investment. London: Office of the Third Sector,.

Pitt, Mark M., Shahidur R. Khandker, Signe-Mary Mckernan, and M. Abdul Latif. 1999. "Credit programs for the poor and reproductive behavior in low-income countries: Are the reported causal relationships the result of heterogeneity bias?" Demography 36 (1):1-21.

Ryan, Patrick W., and Isaac Lyne. 2008. "Social enterprise and the measurement of social value: methodological issues with the calculation and application of the social return on investment." Education, Knowledge and Economy 2 (3):223-237. doi: $10.1080 / 17496890802426253$.

Smith, Stephen C. 2002. "Village Banking and Maternal and Child Health: Evidence from Ecuador and Honduras." World Development 30 (4):707-723. doi: http://dx.doi.org/10.1016/S0305-750X(01)00128-0.

Somers, Alibeth., J. Nicholls, S. Mackenzie, and L. Sanfilippo. 2005. Measuring value creation in Social Firms: a do-it-yourself training manual for SROI. London: New Economics Foundation.

Tarozzi, Alessandro, Jaikishan Desai, and Kristin Johnson. 2015. "The Impacts of Microcredit: Evidence from Ethiopia." American Economic Journal: Applied Economics 7 (1):54-89. 
Figure 1: Organisational

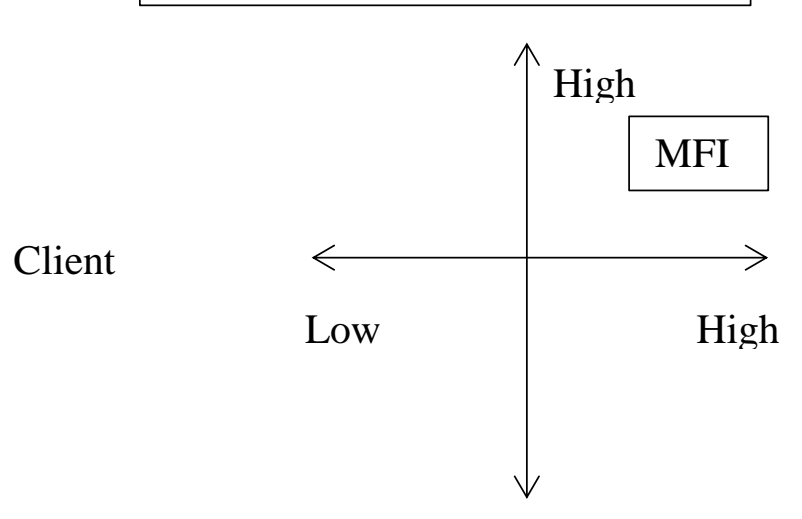

Screening 
Table 1: Impact by impact area and study

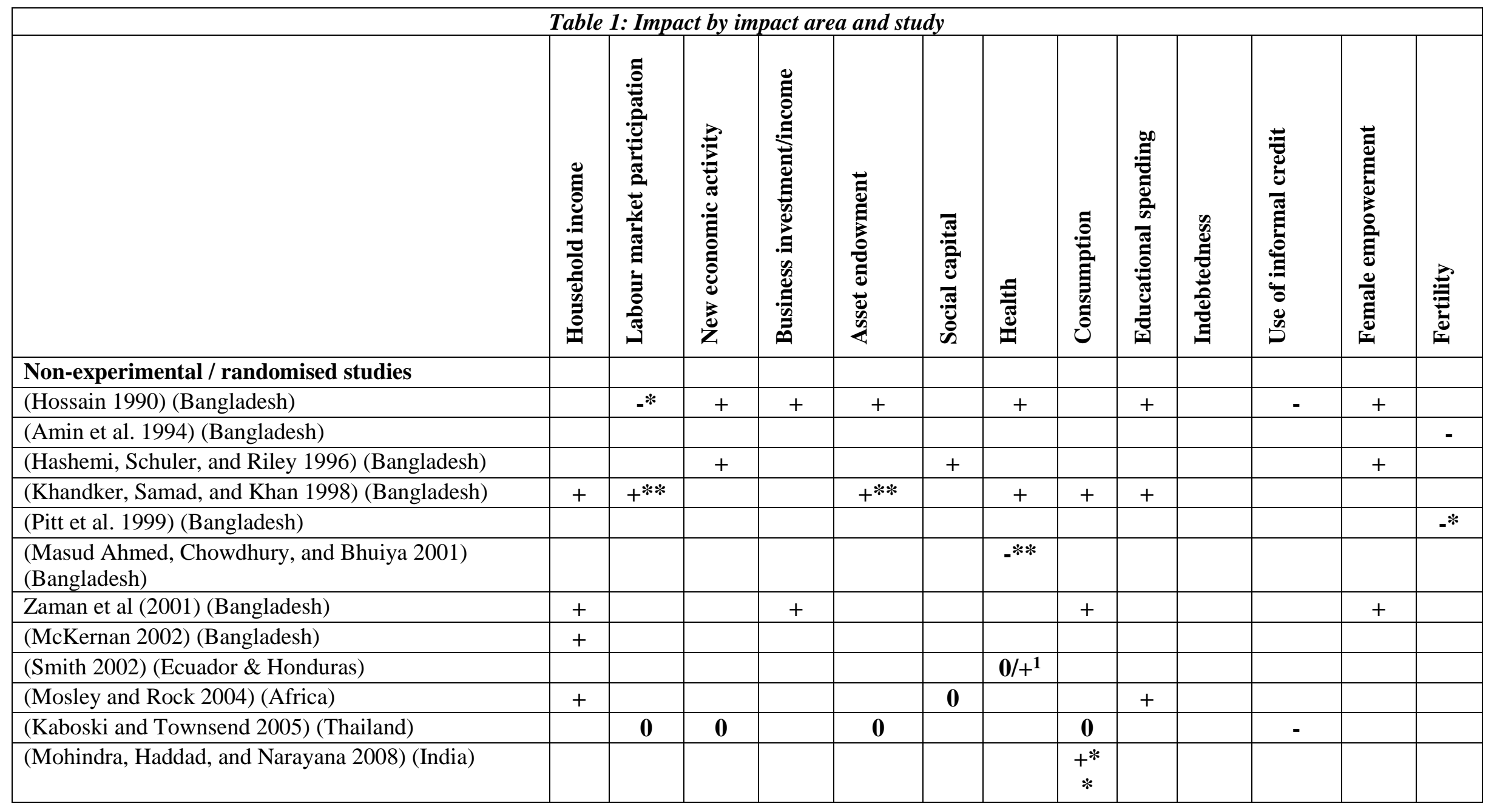

${ }^{1}$ Positive impact in Ecuador on health for microcredit only, and positive impact for microcredit and other health interventions (bundled approach) for both countries. 


\begin{tabular}{|c|c|c|c|c|c|c|c|c|c|c|c|c|c|}
\hline & 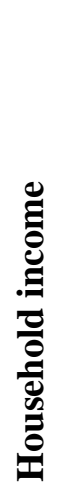 & 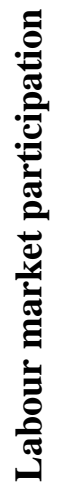 & 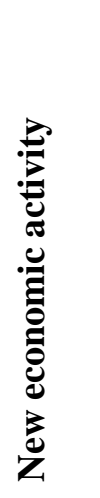 & 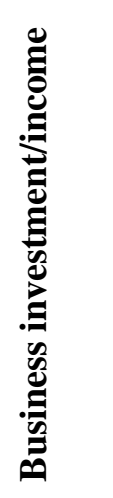 & 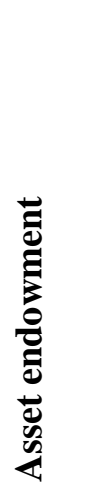 & & 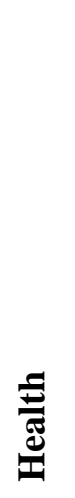 & 泀 & 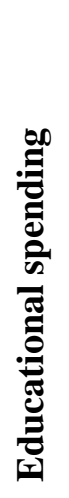 & 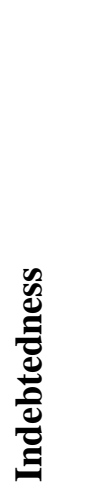 & 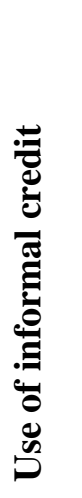 & 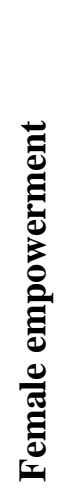 & : \\
\hline \multicolumn{14}{|l|}{ Experimental / randomised studies } \\
\hline (Coleman 1999) (Thailand) & $\mathbf{0}$ & $\mathbf{0}$ & & $\mathbf{0}$ & $\mathbf{0}$ & & $\mathbf{0}$ & & $\mathbf{0}$ & $+* *$ & & & \\
\hline (Fernald et al. 2008) (South Africa) & & & & & & & - & & & & & & \\
\hline (Karlan and Zinman 2010) (Philippines) & $\mathbf{0}$ & & & $+* /-^{2}$ & & & & $\mathbf{0}$ & + & & & & \\
\hline (Angelucci, Karlan, and Zinman 2015) (Mexico) & $\mathbf{0}$ & $\mathbf{0}$ & & + & & & $\mathbf{0}$ & $\mathbf{0}$ & & & & & \\
\hline (Attanasio et al. 2015) (Mongolia) & $\mathbf{0}$ & $\mathbf{0}$ & $\begin{array}{c}+* * \\
*\end{array}$ & & $\mathbf{0}$ & & & $\begin{array}{l}+* \\
* *\end{array}$ & & & $\mathbf{0}$ & & \\
\hline (Augsburg et al. 2015) (Bosnia) & $\mathbf{0}$ & $\mathbf{0}$ & + & + & & & & - & & & & & \\
\hline (Banerjee et al. 2015) (India) & & & + & + & & & $\mathbf{0}$ & $\mathbf{0}$ & $\mathbf{0}$ & & & $\mathbf{0}$ & \\
\hline (Crépon et al. 2015) (Morocco) & $\mathbf{0}$ & - & + & + & + & & $\mathbf{0}$ & $\mathbf{0}$ & $\mathbf{0}$ & & & $\mathbf{0}$ & \\
\hline (Tarozzi, Desai, and Johnson 2015) (Ethiopia) & $\mathbf{0}$ & $\mathbf{0}$ & $\mathbf{0}$ & $\mathbf{0}$ & & & $\mathbf{0}$ & $\mathbf{0}$ & $\mathbf{0}$ & & & $\mathbf{0}$ & \\
\hline \multicolumn{14}{|c|}{$\begin{array}{l}\text { Notes: * only significant for men; ** only significant for women; } * * * \text { only for group lending; } \\
\text { - (negative) }++ \text { (positive), } 0 \text { (no effect) } \\
\text { Year and country/continent in brackets }\end{array}$} \\
\hline
\end{tabular}

${ }^{2}$ Profits increase but treated businesses shrink in terms of number of employees 